PAPER

\title{
Whiplash following rear end collisions: a prospective cohort study
}

\section{H Pobereskin}

J Neurol Neurosurg Psychiatry 2005;76:1146-1151. doi: 10.1136/jnnp.2004.049189

\begin{abstract}
Objective: The purpose of this study was to investigate the factors which predict neck pain initially and at 1 year following a rear end collision.

Methods: All people who reported a rear end collision to the Devon and Cornwall Constabulary were identified and formed the basis of the cohort. People were excluded if they were under 18 years of age or had suffered a head injury. The main outcome measures were neck pain lasting for more than a week after the accident and neck pain at least 1 day a week at 1 year. Logistic regression was used to investigate associations between demographic and accident related variables and outcomes.

Results: A total of 1147 people reported rear end collisions to the police during the study period and 503 $(44 \%)$ agreed to take part in the study. Of the respondents, $78 \%$ had neck pain lasting for more than a week and $52 \%$ still had pain at 1 year. Age (odds ratio, $95 \%$ confidence interval: $0.957,0.942-0.972$ ) and prior history of neck pain $(8.32,2.89-23.89)$ were the most important predictors of early neck pain. The most important predictors of pain at 1 year were the initial neck visual analogue scale (VAS) score $(1.03,1.01-1.05)$ and the presence of a compensation claim $(4.09,1.62-10.32)$. There was only weak evidence that measures of the severity of the impact were associated with outcomes.

Conclusion: Demographic variables and the presence of a compensation suit show the strongest correlation with acute and chronic neck pain following rear end collisions.
\end{abstract}

W hiplash is essentially a symptom complex which has no pathological or radiological correlates. It is generally assumed to be a traumatic condition which follows a specific mechanism of injury. Virtually every previous study has been done on potentially biased opportunistic sampling frames consisting of people who sought medical help following a road traffic accident. There is no information about what proportion of people seek medical attention following such accidents. Believing that the literature accurately reflects the natural history of whiplash requires the assumption that people who do not seek medical help are uninjured. If this is the case then the obvious question is, why are they uninjured? Only in a cohort which includes all those exposed to the traumatic mechanism will it be possible to explore the demographic and accident related factors which characterise the two resultant groups, those that develop symptoms and those that do not.

In 1996, a paper appeared from Lithuania ${ }^{1}$ which did study such a cohort. In contrast to previous studies, all carried out in highly developed Western societies, neck pain was found to last a very short time in this culture where there are few insurance claims and a low expectation of injury. The paper was criticised because it did not study late whiplash when the point was that this entity did not seem to exist in Lithuania.

The present study takes place in the United Kingdom, a country with a robust compensation culture. The sampling frame includes all those exposed to a rear end collision allowing investigation of any differences between those who do and do not seek medical attention. The main aim of this study was to examine the association of demographic and crash related factors to early and late neck pain following rear end collisions.

\section{METHODS}

Ethics approval was obtained from the South and West Devon Local Research Ethics Committee.

\section{Study population}

Between April 1, 2000 and March 31, 2001 and within 2 weeks of the accident, the Devon and Cornwall Constabulary contacted all people (drivers and passengers) who were in rear end collisions reported to them. Frontal and side impacts were excluded. A letter was sent by the police briefly describing the study asking that anyone who agreed to participate return a signed consent form to the author. People contacted were involved in accidents classified by the police as either slight or damage only. This excluded people with serious injuries requiring immediate transfer to hospital. People were secondarily excluded if they were under 18 years of age or had suffered a head injury.

\section{Questionnaires}

A standardised questionnaire was sent to consenting participants. Demographic data requested included date of birth, height, weight, occupation, and past history of car accidents, neck pain, or headache. Accident details requested included make and model of car, year of registration, use of seat belts and headrest, position of headrests relative to the head, estimated speeds of the two cars, occurrence of an associated head injury, whether the two cars were driveable, awareness of the impending accident, and whether the head was straight or turned at the time of impact. Information was requested with regard to visits to the accident and emergency department or the general practioner (GP). Questions asked if there had been any neck pain following the accident and if so when it had started and how long it had lasted. If pain was still continuing, further questions asked as to how many days a week it occurred and, using a visual analogue scale (VAS), we asked for quantification of the pain. An example of how to use a VAS was given in the covering letter. Similar questions were asked about headache, arm pain, and arm tingling. We asked if there had been any problems with memory, concentration, dizziness, swallowing, or vision after 
the accident. We requested the names and addresses of any passengers who would be willing to participate in the study.

Any person who had continuing neck pain at first contact was sent a further questionnaire at 6 months following the accident. On this occasion there were questions about any treatment and medication and about disruption of sleep and time off work. We also asked whether compensation was sought. Subsequent questionnaires were sent at 1 year.

A similar further questionnaire was sent at 2 years to those who were seeking compensation. We asked if the compensation claim had been settled.

If no reply was obtained at any stage a reminder and duplicate questionnaire were sent after 30 days.

\section{Definitions}

The two primary outcome measures in this study were the presence of early and late whiplash. People who continued to have any neck pain more than 7 days following the road traffic accident were deemed to have early whiplash. People with neck pain at least 1 day a week 1 year following the accident were defined as having late whiplash.

People were asked about neck pain in the 6 months prior to the accident and the number of days per week it occurred. Anyone who reported pain at least once a week was considered to have a history of prior neck pain.

Car types were placed in three fairly equal groups using the Automobile Association classification as follows: sports cars, super minis, and city cars were classified "mini", small family cars were classified as "small", and large family cars, executive cars, large and small MPV and SUV were classified as "large".

As well as the neck pain VAS, people were asked to quantify their pain on a three point scale as mild, moderate, or severe. Mild was defined as neck pain which did not interfere with daily activities. Moderate was defined as neck pain which allowed the activities of daily living but stopped participation in sports or other heavy activity. Severe was defined as neck pain which interfered with all activities.

Striking speeds were defined as the difference between the speed of the struck and striking car as estimated by the participant.

\section{Statistics}

Appropriate variables were first examined separately and possible predictive factors were then included in a multivariate analysis. Associations between categorical variables and outcomes were examined with the $\chi^{2}$ test. Between group differences for normally distributed quantitative variables were compared with Student's t test and for nonnormally distributed variables with the Mann-Whitney U test. For multiple group comparisons, analysis of variance with the Bonferroni correction was used. Pearson's correlation coefficients were calculated to examine relationships between discrete quantitative variables.

All factors which showed differences at the $p=0.20$ level or less in the individual analyses were included in the multivariant analysis. Using the likelihood ratio to select variables, logistic regression models were constructed with the forward selection method. -2 log likelihood ratios were calculated for each variable as indicators of the importance of the factor to the final model. All tests were two sided and because of the multiple comparisons carried out significance was assumed at the 0.03 level.

A post hoc sample size calculation showed that the cohort would provide $80 \%$ power to show a between group difference of $4 \mathrm{mph}$ in striking speeds at an $\alpha=0.05$.

Data handling was performed with Microsoft Access V7.0 and statistical analysis with SPSS V8.0.

\section{RESULTS}

The disposition of the cohort is shown in fig 1. A total of 503 people agreed to be in the study and returned the initial questionnaire. Questionnaires were completed 77 (56104) days (median, interquartile (IQ) range) following the accident. The characteristics of the cohort are shown in table 1. Everyone reported wearing a seat belt. Nonresponders were more likely to be younger and male than responders.

\section{Initial outcomes and predictors of early pain}

The initial outcome of the cohort is shown in table 2. A total of 67 people reported no neck pain and a further 45 had neck pain that lasted less than a week. In those with any neck pain following the collision, $44 \%$ had pain beginning within $24 \mathrm{~h}$ and a further $29 \%$ had pain beginning between 24 and $48 \mathrm{~h}$. The latest the pain began was on day 5 in $2 \%$.

While $10.3 \%$ sought no medical help, $48.3 \%$ of the cohort visited both their GP and casualty. A total of $87 \%$ of those who went to their GP had early whiplash, while $83 \%$ of those who went to casualty had early whiplash and $37 \%$ of those who sought no medical help had early whiplash. People who visited their GP had more days per week of neck pain (mean (standard deviation, SD): 3.8 (2.9) days) than those that did not ( 1.9 (2.7) days) $(\mathrm{p}<0.005, \mathrm{t}$ test $)$ and higher initial VAS scores (median (IQ range): $29.5(4.5-54.5))$ than those that did not $(0(0-30))(\mathrm{p}<0.005$, Mann-Whitney U). Those that visited casualty had neck pain on 3.6 (2.9) days per week and those that did not had pain 2.6 (2.9) days per week $(\mathrm{p}<0.005$, t test $)$. The initial neck VAS score for those that visited casualty was $28(3-53)$ versus $16(0-33.5)$ for those that did not $(\mathrm{p}<0.005$, Mann-Whitney $\mathrm{U})$.

Potential predictors of early whiplash are listed in table 3. Analysed individually, eight factors appeared to be possible predictors of those people who would suffer early whiplash. A logistic regression model was constructed using these variables ( $\log$ likelihood 420.77, $\left.\mathrm{R}^{2} 0.241\right)$. In this model five factors independently predicted early whiplash (table 4). Three demographic variables contributed the most to the model. Two accident related factors were also statistically significant.

\section{Late outcomes and predictors of chronic pain}

Of the 391 people with early whiplash, 315 (80.5\%) responded to a questionnaire sent 1 year following their accident. Non-responders were younger (mean (SD): 37.5 (12.0) years) than those who did respond (42.7 (15.1) years) $(\mathrm{p}=0.002$, t test $)$. A greater proportion of non-responders were male $(39.5 \%)$ than in the responder group $(28.7 \%)$, but this was not statistically significant $(\mathrm{p}=0.074)$. There was no difference between responders and non-responders with regard to initial neck VAS score or the number of days per week they had neck pain.

At 1 year, 164 (52.1\%) of the total of 315 responders still had neck pain at least 1 day a week. A total of 121 people who reported no previous history of neck pain had pain at 1 year. Of those with late whiplash, $66(40.2 \%)$ rated their neck pain as mild, $79(48.2 \%)$ rated their pain as moderate, and $19(11.6 \%)$ rated their pain as severe. Forty five $(27 \%)$ people had neck pain 1 or 2 days a week, 31 (19\%) people had pain 3 or 4 days a week, 22 (13\%) had pain 5 or 6 days a week and $66(40 \%)$ complained of pain 7 days a week.

The characteristics of the 315 responders in relation to late whiplash are listed in table 5. Twelve factors when analysed separately appeared to be potential predictors of pain at 1 year. The results are shown in table 6 . The final model had a $-2 \log$ likelihood of 304.87 and an $\mathrm{R}^{2}$ of 0.455 . The most important predictors of pain at 1 year were initial VAS score and compensation. 


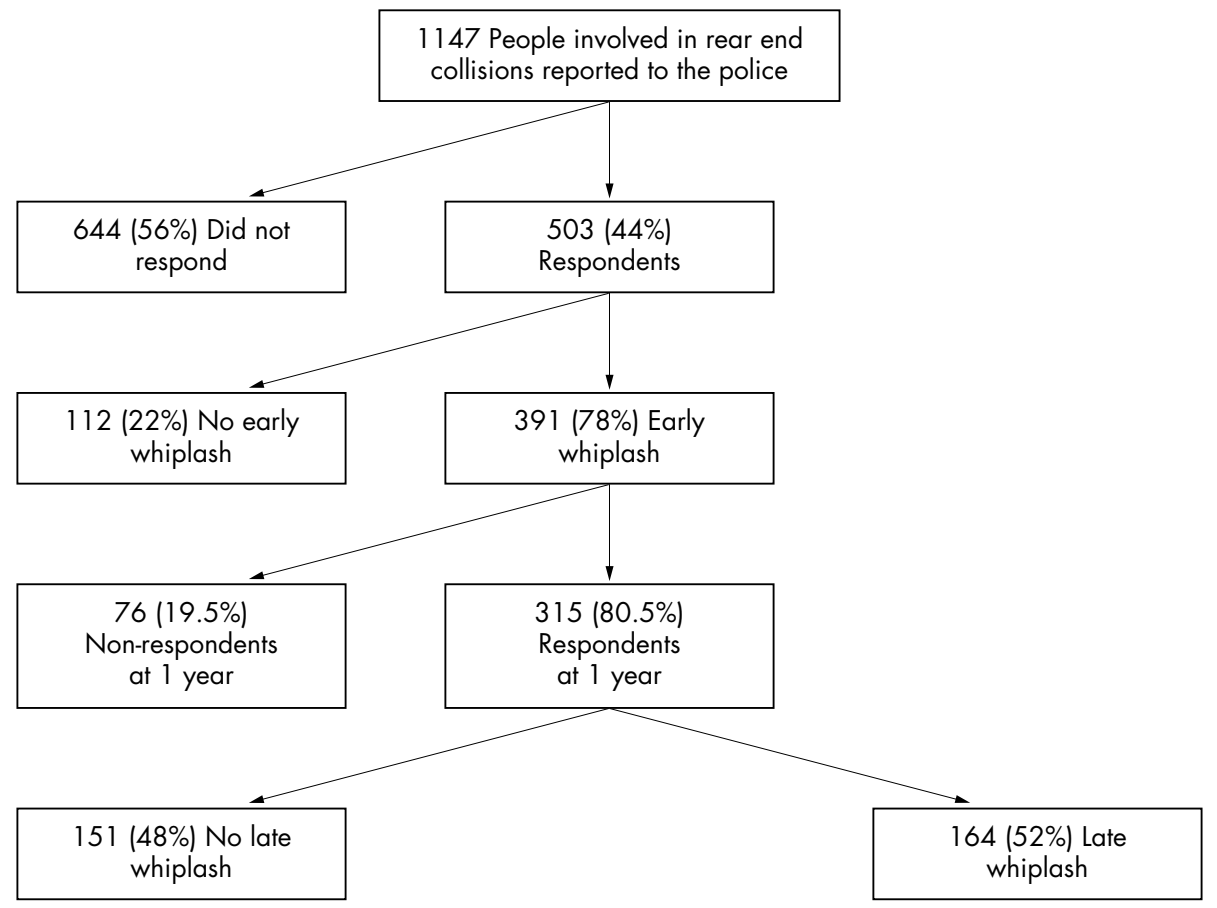

Figure 1 The disposition of the cohort.

\section{Employment outcomes and crash related factors}

Of the 447 people who reported being employed at the time of the index accident, 111 (25\%) had some time off work: 68 $(61 \%)$ had a month or less off and a further $27(24 \%)$ had between 1 and 6 months off. Two people (2\%) had between 6 and 12 months off work and $14(13 \%)$ were still off work at 1 year.

The proportion of struck cars that were drivable increased with vehicle size from mini $(57.8 \%)$ to small $(60.3 \%)$ and large $(71.7 \%) \quad\left(p=0.01, \chi^{2}\right.$ for trend $)$. Conversely, the drivability of the striking car decreased from mini $(69.4 \%)$ to small $(58.6 \%)$ and large $(57.9 \%)\left(p=0.03, \chi^{2}\right.$ for trend). There was no difference in striking speeds between the car classes. Striking speeds were significantly higher when the struck car was not drivable (mean (SD): 32.2 (13.78) $\mathrm{mph}$ ) than when it was $(26.8(10.61) \mathrm{mph})(\mathrm{p}<0.005, \mathrm{t}$ test $)$. There was no correlation between initial neck VAS scores and striking speeds (Pearson correlation $=-0.041$ ). There was no relationship between striking speeds and the number of days the participant had neck pain (ANOVA, $p=0.11$ ). Similarly,

\begin{tabular}{|c|c|c|c|}
\hline Characteristic (number missing data) & Respondents, $\mathbf{n}(\%)$ & Non-respondents, n (\%) & p Value \\
\hline Total & $503(44 \%)$ & $644(56 \%)$ & \\
\hline Female & $332(66 \%)$ & $352(55 \%)$ & $<0.005^{*}$ \\
\hline Age, median (IQ range) & $43(31-55)$ & $34.5(24-45)$ & $<0.005 \dagger$ \\
\hline BMI, median (range) & $25.7(16.2-43.7)$ & & \\
\hline Previous neck pain & $89(17.7 \%)$ & & \\
\hline Current smoker (7) & 101 (20.1\%) & & \\
\hline Married & 362 (72\%) & & \\
\hline \multicolumn{4}{|l|}{ Occupation (17) } \\
\hline Unemployed or housewife & $44(8.7 \%)$ & & \\
\hline Unskilled & $120(23.9 \%)$ & & \\
\hline Semi-skilled & $185(36.8 \%)$ & & \\
\hline Skilled & $61(15.1 \%)$ & & \\
\hline Professional or managerial & 76 (15.1\%) & & \\
\hline Visited casualty & $330(65.6 \%)$ & & \\
\hline Visited GP & 364 (72.4\%) & & \\
\hline \multicolumn{4}{|l|}{ Car size (4) } \\
\hline Mini & 173 (34.7\%) & & \\
\hline Small & 174 (34.9\%) & & \\
\hline Large & $152(30.5 \%)$ & & \\
\hline Headrest present & $460(91.5 \%)$ & & \\
\hline Correct headrest position (111) & 197 (39.2\%) & & \\
\hline Aware of collision & $121(24.1 \%)$ & & \\
\hline Head turned & $156(31 \%)$ & & \\
\hline Struck car driveable & $314(62.4 \%)$ & & \\
\hline Striking car driveable & $310(61.6 \%)$ & & \\
\hline Struck car stationary & 399 (79.3\%) & & \\
\hline Striking speed, mph (23), mean (SD) & $28.8(12.1)$ & & \\
\hline
\end{tabular}


Table 2 Early outcomes

\begin{tabular}{lr}
\hline Outcome & Number (\%) \\
\hline Early whiplash & $391(77.7 \%)$ \\
Headache & $226(44.9 \%)$ \\
Arm pain & $148(29.4 \%)$ \\
Low back pain & $142(28.2 \%)$ \\
Concentration problems & $170(33.8 \%)$ \\
Memory problems & $93(18.5 \%)$ \\
Dizziness & $103(20.5 \%)$ \\
Neck pain severity* & $101(25.8 \%)$ \\
Mild & $185(47.3 \%)$ \\
Moderate & $48(12.2 \%)$ \\
Severe & *nly those still having neck pain at first questionaire. \\
\hline *
\end{tabular}

there was no association between striking speeds and neck pain severity initially or at 1 year or neck VAS scores at 1 year.

\section{Outcomes in those seeking compensation}

A total of $236(75 \%)$ responders at 1 year were seeking compensation. A total of $204(86.4 \%)$ answered a questionnaire at 2 years and 70 of these (34.3\%) had settled their claim. Those that settled and those that had not were virtually identical in age (mean (SD): 43.4 (15.3) years and 42.5 (14.1) years, respectively) and gender ( $75.7 \%$ and $72.4 \%$ female, respectively). At 2 years people who had settled were more likely to have neck pain at least once a week $(70 \%)$ than those that had not settled $(56.7 \%)(p=0.064)$. Neck VAS scores (median, IQ range) were very similar at 18 (1.8-34.3) and $17.5(8-27)$, respectively.

\section{DISCUSSION}

The nosological validity of whiplash as a traumatic injury has been under increasing attack in recent years. ${ }^{2}$ Stover reviewed the literature in 1996 and suggested that the Bradford-Hill criteria for assessing the association of an environmental factor with a disease were poorly fulfilled in the case of whiplash. ${ }^{3}$ In particular, he was disturbed that there is no evidence of a dose-response relationship between the severity of the trauma and subsequent symptoms.

In so far as this cohort represents the experience of people involved in rear end collisions in the United Kingdom, the
Table 4 Final model with six independent predictors of early whiplash

\begin{tabular}{lll}
\hline Variable & Odds ratio $(95 \% \mathrm{Cl})$ & $\begin{array}{l}\text { Likelihood } \\
\text { ratio } \chi^{2 *}\end{array}$ \\
\hline Age & $0.957(0.942-0.972)$ & 34.05 \\
Previous neck pain & $8.32(2.89-23.89)$ & 25.55 \\
Occupational class & & 8.49 \\
$\quad \begin{array}{l}\text { Professional and managerial } \\
\quad \text { Semi-skilled or skilled }\end{array}$ & 1.00 & \\
$\quad$ Unemployed or unskilled & $0.01(1.04-3.86)$ & \\
Car size & $10.49-1.91)$ & 7.98 \\
$\quad$ Mini & 1.00 & \\
$\quad$ Small & $1.74(0.99-3.04)$ & \\
$\quad$ Large & $2.29(1.24-4.19)$ & 7.39 \\
Struck car stationary & $2.15(1.25-3.71)$ & 7.25 \\
\hline
\end{tabular}

*Obtained as the change in the model deviance $(-2 \log ($ likelihood)) that results when each covariate is removed from the full six covariate model. $95 \% \mathrm{Cl}, 95 \%$ confidence interval.

analysis suggests that demographic variables are the most important in predicting early neck pain. At 1 year the severity of the initial neck pain is highly associated with chronic neck pain as is the presence of a compensation suit. There is little evidence that the severity of the impact predicts the early onset of neck pain or pain at 1 year.

The primary strength of this study is that it takes as its sampling frame all those exposed to a specific mechanism of injury known to be associated with whiplash. As any insurance claim requires a police report, virtually all rear end collisions should have been captured. With all that has been written about whiplash, it is surprising that the present study is the first to use multivariant analysis to investigate such a cohort. The most commonly quoted previous studies are all potentially biased as the cohorts were drawn from those attending casualty, ${ }^{4-6}$ or their $\mathrm{GP}^{78}$ or for tertiary opinions or medico-legal reports. ${ }^{9-11}$ The study's other strength is the size of the cohort. Except for those using routinely collected insurance company data, most previous studies have included less than 100 people.

The primary limitation of this study is the response rate of $44 \%$ to the original request to take part. It is difficult to see how this can be improved upon without a change in the attitude of the public to medical research. In contrast to

Table 3 Potential predictors of early whiplash

\begin{tabular}{|c|c|c|c|}
\hline Characteristic (number missing data) & No early whiplash, $n$ (\%) & Early whiplash, n (\%) & p Value \\
\hline Total number & $112(22 \%)$ & $391(78 \%)$ & \\
\hline Female & $67(59.8 \%)$ & $265(67.8 \%)$ & $0.117^{*}$ \\
\hline Age, median (IQ range) & $52(39.2-69)$ & $40(30-53)$ & $<0.005 \dagger$ \\
\hline $\mathrm{BMI}$, median (IQ range) & $25.8(23.7-27.8)$ & $25.7(23.2-29.6)$ & $0.650 \dagger$ \\
\hline Previous neck pain & $4(3.6 \%)$ & $85(21.7 \%)$ & $<0.005^{*}$ \\
\hline Current smoker (7) & $19(17.3 \%)$ & $82(21.2 \%)$ & $0.362^{*}$ \\
\hline Married & $85(75.9 \%)$ & $277(70.8 \%)$ & $0.294^{*}$ \\
\hline Occupation (17) & & & $0.088^{*}$ \\
\hline Unemployed or unskilled & $43(40.2 \%)$ & $121(31.9 \%)$ & \\
\hline Semi-skilled or skilled & $42(39.3 \%)$ & $204(53.8 \%)$ & \\
\hline Professional or managerial & $22(20.6 \%)$ & $54(14.2 \%)$ & \\
\hline Car size (4) & & & $0.033^{*}$ \\
\hline Mini & $48(44 \%)$ & $125(32.1 \%)$ & \\
\hline Small & $37(33.9 \%)$ & $137(35.1 \%)$ & \\
\hline Large & $24(22 \%)$ & $128(32.8 \%)$ & \\
\hline Headrest present & $103(92 \%)$ & $357(91.3 \%)$ & $0.826^{*}$ \\
\hline Aware of impending collision & $26(23.2 \%)$ & $95(24.3 \%)$ & $0.813^{*}$ \\
\hline Head turned & $26(23.2 \%)$ & $130(33.2 \%)$ & $0.043^{*}$ \\
\hline Struck car driveable & $64(57.1 \%)$ & $250(63.9 \%)$ & $0.190^{*}$ \\
\hline Striking car driveable & $65(58 \%)$ & $245(62.7 \%)$ & $0.375^{*}$ \\
\hline Struck car stationary & $75(67 \%)$ & $324(82.9 \%)$ & $<0.005^{*}$ \\
\hline Speed difference (15), mean (SD) & $27.2(12.7)$ & $29.1(11.9)$ & $0.307 \ddagger$ \\
\hline
\end{tabular}

${ }^{*} \chi^{2}$; † Mann Whitney $U ; \ddagger$ Student's $\uparrow$ test.

$\mathrm{BMI}$, body mass index. 
Table 5 Potential predictors of late whiplash

\begin{tabular}{|c|c|c|c|}
\hline \multirow[b]{2}{*}{ Characteristic (number missing data) } & \multirow{2}{*}{$\begin{array}{l}\text { No late whiplash } \\
\text { Number (\%) }\end{array}$} & \multirow{2}{*}{$\begin{array}{l}\text { Late whiplash } \\
\text { Number (\%) }\end{array}$} & \multirow[b]{2}{*}{ p Value } \\
\hline & & & \\
\hline Total number & $151(48 \%)$ & $164(52 \%)$ & \\
\hline Female & $100(66.2 \%)$ & $119(72.6 \%)$ & $0.222^{*}$ \\
\hline Age, mean (SD) & $41.9(15.9)$ & $43.8(14.2)$ & $0.293 \ddagger$ \\
\hline $\mathrm{BMI}$, median (IQ range) & $26.1(23.1-29.1)$ & $25.7(22.5-28.9)$ & $0.660 \dagger$ \\
\hline Previous neck pain & $27(17.9 \%)$ & $43(26.2 \%)$ & $0.075^{*}$ \\
\hline Current smoker (5) & $27(18.1 \%)$ & $2622.4 \%)$ & $0.354^{*}$ \\
\hline Married & $111(72.8 \%)$ & $118(72 \%)$ & $0.859^{*}$ \\
\hline Seeking compensation & $81(53.6 \%)$ & $155(94.5 \%)$ & $<0.005^{*}$ \\
\hline Occupation (10) & & & $0.800^{*}$ \\
\hline Unemployed or unskilled & $47(32 \%)$ & $54(34.2 \%)$ & \\
\hline Semi-skilled or skilled & $78(53 \%)$ & $82(51.9 \%)$ & \\
\hline Professional or managerial & $22(15 \%)$ & $22(13.9 \%)$ & \\
\hline Car size & & & $0.073^{*}$ \\
\hline Mini & $61(40.4 \%)$ & $47(28.7 \%)$ & \\
\hline Small & $51(33.8 \%)$ & $61(37.2 \%)$ & \\
\hline Large & $39(25.8 \%)$ & $56(34.1 \%)$ & \\
\hline Aware of collision & $39(25.8 \%)$ & $41(25 \%)$ & $0.866^{*}$ \\
\hline Head turned & $45(29.8 \%)$ & $62(37.8 \%)$ & $0.134^{*}$ \\
\hline Struck car driveable & $93(61.6 \%)$ & $107(65.2 \%)$ & $0.501^{*}$ \\
\hline Striking car driveable & $85(56.3 \%)$ & $110(67.1 \%)$ & $0.049^{*}$ \\
\hline Struck car stationary & $134(88.7 \%)$ & $132(80.5 \%)$ & $0.043^{*}$ \\
\hline Striking speed (12), mean (SD) & $30.1(12.5)$ & $29(11.6)$ & $0.420 \ddagger$ \\
\hline Initial days of pain/week, mean (SD) & $2.6(2.8)$ & $5.3(2.1)$ & $<0.005 \ddagger$ \\
\hline Initial neck VAS score, median (IQ range) & $18(2-34)$ & $44(27.3-60.8)$ & $<0.005 \dagger$ \\
\hline Initial headache & $52(34.4 \%)$ & $111(67.7 \%)$ & $<0.005^{*}$ \\
\hline Initial arm pain & $27(17.9 \%)$ & $81(49.4 \%)$ & $<0.005^{*}$ \\
\hline Initial low back pain & $42(27.8 \%)$ & $54(32.9 \%)$ & 0.325 \\
\hline Initial concentration problems & $48(31.8 \%)$ & $73(44.5 \%)$ & $0.020^{*}$ \\
\hline Initial memory problems & $25(16.6 \%)$ & $42(25.6 \%)$ & $0.050^{*}$ \\
\hline Initial dizzyness & $32(21.2 \%)$ & $44(26.8 \%)$ & $0.243^{*}$ \\
\hline
\end{tabular}

previous studies, however, the characteristics of those who participated and those that did not are clearly understood. Non-responders, as in many studies, were younger than responders and more likely to be male. The response rate in this study is lower than previous more biased samples in the literature of whiplash and the results will be less generalisable as a consequence. There was no association between gender and outcomes so the fact that males were less likely to respond should have made no difference. Age had no correlation with late neck pain but early neck pain risk seemed to decrease with increasing age so that the results here may actually underestimate the proportion with neck pain early on.

Until this study there was no information about what proportion of people exposed to rear end collisions sought medical attention. In this population about three quarters of people went to their GP and two thirds attended casualty. Not surprisingly, these groups represent the more seriously injured end of the spectrum. About a tenth of people seek no medical help, and yet almost $40 \%$ of this group report having early neck pain.

Table 6 Final model with five independent predictors of late whiplash

\begin{tabular}{lll}
\hline Variable & Odds ratio $(95 \% \mathrm{CI})$ & $\begin{array}{l}\text { Likelihood } \\
\text { ratio } \chi^{2 *}\end{array}$ \\
\hline Neck VAS score & $1.03(1.01-1.05)$ & 10.82 \\
Compensation claim & $4.09(1.62-10.32)$ & 9.72 \\
Struck car stationary & $0.31(0.13-0.71)$ & 8.28 \\
Arm pain & $2.23(1.08-1.22)$ & 6.93 \\
Days of neck pain/week & $1.18(1.03-1.35)$ & 5.98 \\
\hline *Obtained as the change in the model deviance (-2log(likelihood)) that \\
results when each covariate is removed from the full five covariate model. \\
95\% Cl, 95\% confidence interval.
\end{tabular}

The forces transmitted to the cervical spine in this situation are complex and difficult to measure outside a crash laboratory. Factors related to seat and bumper construction as well as car "crumple" zones can, of course, influence the forces involved. Nevertheless, it is surprising that it has not been possible to relate estimated striking speeds to early whiplash or to any measure of neck pain severity either early on or at 1 year. This is not the first time this has been reported. In a study of 173 people who attended casualty after rear end collisions, Kasch et al reported no relationship between striking speeds and neck mobility, neck pain, or headache. ${ }^{12}$ They also found no relationship between car weight differences and any of the above factors. Estimations of striking speeds may clearly be inaccurate. If any bias exists, however, one would expect those more severely injured to be more likely to overestimate speed differences than those with minor injuries. The fact that car drivability was associated logically with estimated striking speeds suggests some validity for the measure.

Previous studies have suggested a number of crash related factors that influence outcome, including rotation of the head and lack of awareness of the collision, ${ }^{8}$ and presence of a seat belt. ${ }^{13}$ In this cohort the influence of seat belts could not be studied as everyone reported using them. If neck pain following rear end collision arises from specific traumatic pathophysiological mechanisms, it would seem logical on anatomic and physiologic grounds that rotation of the head and lack of awareness of the impending collision would increase risk of acute symptoms. In this study, neither of these factors were predictive.

In the present cohort, two accident related factors, car size and the struck car being stationary, were minor contributors to the model of early pain. The fact that driving a large car increased risk seems counterintuitive, however, a greater proportion of large cars were drivable after the accident. This may imply that large cars are less likely to deform and 
therefore more of the energy of the collision was transmitted to the occupants. The small contribution of this variable to the odds of early neck pain is the only indication of a relationship between severity of impact and outcome.

The fact that being stationary when struck increases neck symptoms early on and yet is protective at l year is confusing. It is possible that some unmeasured confounder such as head rest position or seat construction accounts for this result. Although not used in the analysis because of the large number of missing values, equal percentages of people in the stationary and moving groups reported correct head rest position. It is interesting to speculate that there may be a psychological difference between these two groups. People stationary when hit may feel more "innocent" than those that were moving.

The proportion of people suffering from continued neck pain at 1 year is within the wide range of values found by other studies. It is unsurprising that the severity of the initial neck pain predicts the final outcome, but the remarkable finding is the strong association of the presence of a legal claim with late pain. This adds to the evidence that methods of compensation may have significant effects on long term outcome in this entity. Studies from countries with low expectations of compensation including Lithuania, ${ }^{14}$ Greece, ${ }^{15}$ and Germany, ${ }^{16}$ have shown no long term increase in neck pain in people exposed to rear end collisions.

Mayou and Bryant studied a range of people attending casualty including 570 people with whiplash. ${ }^{17}$ This study showed that compensation claims did not influence psychological symptoms at 1 year but did predict pain. People seeking compensation were 4.27 (1.6-1 1.1) (odds ratio (95\% $\mathrm{CI})$ ) times more likely to have pain at 1 year than those who were not. This result is strikingly similar to that obtained in this cohort. Cassidy et al showed that eliminating compensation for pain and suffering decreased the incidence and improved the prognosis of insurance claimants after traffic accidents. ${ }^{18}$ This study has been criticised for using a surrogate end point but there is evidence that symptomatic recovery and better function are associated with faster timeto-claim-closure. ${ }^{19}$

Although it is increasing that methods of compensation have an important influence on recovery from whiplash, in this cohort there was no improvement in symptoms once the claim was settled. In fact, people who had settled their claim by 2 years seemed more likely to have neck pain of similar severity compared to those who had ongoing claims. This suggests that there is something about the stress and anxiety of the claim itself that tends to prolong symptoms in people seeking compensation. The various stages of the legal process require people to repeatedly recount the accident and encourages them to report symptoms and the ways they affect their lives. It would not be surprising if this prolongs symptoms and increases their severity. It would appear that once a pain pattern has been established it does not resolve with claim settlement.

\section{ACKNOWLEDGEMENTS}

I would like to thank Steven Willey of the Devon and Cornwall Constabulary for his help in collecting the data, Professor Rob Snyed for his helpful comments on the manuscript, and Steve Shaw for his help with the statistical analysis.

Competing interests: I occasionally write medico-legal reports in personal injury cases. There are no other conflicts.

\section{REFERENCES}

1 Schrader H, Obelieniene D, Bovim G, et al. Natural evolution of late whiplash syndrome outside the medicolegal context. Lancet 1996;347:1207-11.

2 Ferrari R, Schrader H. The late whiplash syndrome: a biopsychosocial approach. J Neurol Neurosurg Psychiatry 2001;70:722-6.

3 Stover $L$. The nosological status of the whiplash syndrome: a critical review based on a methodological approach. Spine 1996;21:2735-46.

4 Mayou R, Bryant B. Outcome of whiplash neck injury. Injury 1996;27:617-23

5 Norris $\mathrm{SH}$, Watt I. The prognosis of neck injuries resulting from rear-end vehicle collisions. J Bone Joint Surg Br 1983;65:608-11.

6 Pennie B, Agambar L. Patterns of injury and recovery in whiplash. Injury 1991;22:57-9.

7 Radanov B, Sturzeneger M, Di Stenfano G. Long-term outcome after whiplash injury: a 2 year follow-up considering features on injury mechanism and somatic, radiologic and psychosocial findings. Medicine 1995;74:281-97.

8 Sturzeneger M, Radanov BP, Di Stenfano G. The effect of accident mechanisms and initial findings on the long term course of whiplash injury. J Neurol 1995;242:443-9.

9 Garagan MF, Bannister GC. Long-term prognosis of soft tissue injuries of the neck. J Bone Joint Surg Br 1990;72:901-3.

10 Hohl M. Soft-tissue injuries of the neck in automobile accidents. J Bone Joint Surg Am 1974;56:1675-82.

11 Parmar HV, Raymakers R. Neck injuries from rear impact road traffic accidents: prognosis in persons seeking compensation. Injury 1993;24:75-8.

12 Kasch H, Stengaard-Pedersen K, Arendt-Nielsen L, et al. Headache, neck pain and neck mobility after acute whiplash injury. Spine $2001 ; 26: 1246-51$.

13 Nygren A. Injuries to car occupants: some aspects of interior safety of cars. A study of a five-year material from an insurance company. Acta Otolaryngol 1984;395:1-164.

14 Obelieniene D, Schrader H, Bovim G, et al. Pain after whiplash: a prospective controlled inception cohort study. I Neurol Neurosurg Psychiatry 1999;66:279-83.

15 Partheni M, Constantayannis C, Ferrari R, et al. A prospective cohort study of the outcome of acute whiplash injury in Greece. Clin Exp Rheumatol 2000;18:67-70.

16 Bonk A, Ferrari R, Giebel GD, et al. A prospective randomized, controlled outcome study of two trials of therapy for whiplash injury. J Musculoskelet Pain 2000;8:123-32.

17 Mayou R, Bryant B. Psychiatry of whiplash neck injury. Br J Psychiatry 2002;180:441-8.

18 Cassidy JD, Carroll $\sqcup$, Cote $P$, et al. Effect of eliminating compensation for pain and suffering on the outcome of insurance claims for whiplash injury. N Engl J Med 2000;342:1179-86.

19 Cote $\mathrm{P}$, Hogg-Johnson S, Cassidy JD, et al. The association between neck pain intensity, physical functioning, depressive symptomatology and time-to-claimclosure after whiplash. J Clin Epidemiol 2001;54:275-86. 